DOI: 10.12957/demetra.2015.16059

\title{
¿Producción de alimento o cultivares de la vida? Observaciones sobre la acción y la contemplación guaraní en sus cultivos agrícolas
}

\section{Food prodution ar altivation of life 2 Remarks on the Guarani action and contemplation in their agricultural cultivars}

\author{
Rubia Carla Formighieri Giordani \\ ' Universidade Federal do Paraná, \\ Departamento de Nutrição, Setor de Ciências da \\ Saúde. Curitiba-PR, Brasil \\ Financiamento: CAPES Processo 2307-10-3 \\ Correspondência / Correspondence \\ Rubia Carla Formighieri Giordani \\ E-mail: rubia@ufpr.br
}

\section{Resumen}

Este artículo presenta una etnografía producida entre los guaraníes contemporáneos de la parcialidad étnica mbya que residen en área indígena en el Estado de Paraná, procurando explotar cómo las actividades dirigidas a la producción de alimentos se unen profundamente en el pensamiento guaraní a los aspectos existenciales y a la relación con lo divino. El cultivo de plantas para la alimentación humana produce entre los guaraníes formas específicas de constitución y reproducción de su mundo social. Las acciones diarias implicadas en el crecimiento de los vegetales deben estar en equilibrio con las actitudes contemplativas posibilitando experimentar concomitantemente las dimensiones ordinaria y sagrada de la vida humana guaraní en la tierra. Así se puede considerar la agricultura manifestando una forma laboriosa de fabricación del interior, de la vida doméstica, pero también su fuerza en la actualización de las relaciones con el dominio exterior, el socius, expresando, a su modo, la dependencia al mundo guaraní de sus dioses. La producción vegetal estaría al mismo tiempo actualizando la condición guaraní y su descendencia de la divinidad, además de reproducir simultáneamente, en la morada de los dioses y aquí en la tierra, las plantas sagradas.

Palabras clave: Guaraní. Cultura Alimentaria. Sagrado. Prácticas Agrícolas. 


\section{Abstract}

This article presents an ethnography produced among the contemporary Guarani of mbya ethnic group living in indigenous land in the state of Paraná, Brazil, by exploring how the activities directed to food production connect deeply with the Guarani thoughts regarding existential aspects and the relationship with divinity. Growing plants for human consumption produces specific forms of constitution and reproduction of the social world for the Guarani. Daily actions involved in the growth of vegetables must balance with contemplative attitudes, enabling the concomitant experience of the ordinary and sacred dimensions of Guarani human life on the land. So, it can be considered that agriculture manifests a laborious way to manufacture the interior, the domestic life, but also its strength to update relations with the outside domain to the socius, expressing the dependence of the Guarani on their gods. Plant production would update, at the same time, the Guarani condition and its seed of divinity, beyond the simultaneous reproduction of sacred plants in the home of the gods and here on earth.

Key words: Guarani. Food Culture. Sacred. Agricultural Practices.

La participación de los cultivares en la dieta guaraní está notoriamente documentada desde la historiografía colonial ${ }^{1,2}$ hasta las etnografías del siglo pasado. Chase-Sardi, ${ }^{3}$ Schaden $^{4}$ y Cadogan ${ }^{5}$ destacaron la persistencia de los rozados, principalmente el cultivo del maíz, entre los diferentes grupos guaraníes en Paraguay y en el suroeste brasileño. Schaden ${ }^{4}$ que los consideraba esencialmente agrícolas, destaca el "carácter comunitario de producción y consumo", como forma auténtica de su organización social teniendo como base la familia numerosa. Aún podemos encontrar en el conjunto de etnografías contemporáneas en los trabajos de Ladeira, ${ }^{6,7}$ Garlet $^{8}$ y de una descripción detallada de la relación entre los desplazamientos, territorios, la (re)conquista y la producción de un bienestar colectivo de aquello que convencionalmente se denominó en la etnografía guaraní, teko. ${ }^{9}$ Los autores destacan el papel privilegiado de la práctica de la agricultura, principalmente del cultivo del maíz y su permanencia, posiblemente, asociada al uso ritual en la importante ceremonia de nombramiento de los niños, el ñemongarai.

* Sesiones de cante y rezo realizadas en la época considerada de renovación para los guaraníes denominado el ara pyau, que coincide con la cosecha del maíz. En este ritual, la divinidad revela el nombre de los niños al chamán-nombrador. 
Este artículo presenta una etnografía ${ }^{10,11}$ producida entre los guaraníes contemporáneos de la parcialidad étnica mbya que viven y se desplazan en áreas indígenas del extremo oeste de Paraná, Paraguay y Argentina. A partir de narrativas míticas, diálogos y datos de observación directa en el campo etnográfico realizado en la Tierra Indígena Itamarã/Paraná, presento una descripción de la relación que los guaraníes de la parcialidad étnica mbya mantienen con el lugar donde viven y cultivan sus alimentos, buscando investigar la productividad de dicha actividad en el campo sociológico y simbólico.

A lo largo del texto se podrá notar cómo ciertos aspectos de la conducta alimentaria, claramente aquellos relacionados a los valores positivos que los vegetales asumen en la dieta guaraní, ${ }^{12-14}$ se mantienen por su origen cosmológico, del mismo modo que su cultivo, visto como posibilidad de reactualización de la unión con los dioses en su vida en este mundo (Yvy Pyau).

El cultivo de plantas en los rozados y al alrededor de sus casas ultrapasa la esfera alimentaria y adquiere productividad simbólica particular en el modo de vida guaraní. ${ }^{15}$ A la luz de su pensamiento, la producción de los alimentos engendra formas específicas de sociabilidad ${ }^{16}$ alineadas a los mecanismos de constitución y reproducción de su mundo, es decir, a aquellos en que se reconocen y se identifican como guaraníes. En la vida doméstica, en sus rozados y áreas contiguas a las casas, las acciones diarias ${ }^{17,18}$ implicadas en el cultivar de plantar deben estar en equilibrio con las actitudes contemplativas posibilitando experimentar concomitantemente las dimensiones ordinaria y sagrada de la vida humana guaraní en la tierra.

\section{Consideraciones sociológicas y cosmológicas sobre las prácticas agrícolas}

Hay una historia originaria sobre el kokue (roza), narrada por el chamán Karai Poty de Itamarã que cuenta que fueron los dioses quienes hicieron levantar las plantas a los guaraníes. Cuenta el mito que una pareja buscaba un lugar donde hacer su kokue y después de mucho caminar, encontraron un espacio que consideraron bueno para sembrar. Con una pequeña hacha hecha a partir de un trozo de madera y una piedrecita afilada limpiaron el mato y después prendieron fuego. Al final del día, cuando todo estaba limpio y la tierra preparada para recibir la semilla, no sabían qué hacer. Pensaban sobre qué podrían sembrar, pero no sabían dónde ir a buscar semillas fértiles para que la tierra preparada por ellos produjera. Nanderu Tupã (divinidad) mandó una fuerte lluvia por la noche que al día siguiente hizo levantar calabazas, cacahuetes, sandías y otras plantas que los guaraníes perpetúan desde entonces en sus rozas.

En Itamarã, los espacios para los rozados son frecuentemente abiertos en el área limítrofe entre la casa y el mato. Tras el derrumbe de la vegetación, con el auxilio de herramientas de metal como machetes y azadas, la limpieza de la vegetación se hace por la quema. ${ }^{19}$ La apertura de nuevos rozados es una etapa considerada dura y normalmente realizada por intermedio de redes de 
cooperación entre familias. Allí, la persistencia de los cultivares presenta diferentes matices en sus formas contemporáneas, manteniéndose el cultivo conjugado de algunas especies vegetales para las cuales las mujeres dan destino en su cocina con variadas técnicas culinarias. De estas plantas, según me han dicho, preparan comida de uso ritual en la opy (casa de rezo), en la comida para hacer que crezcan los niños, alimentar a personas, circular entre los parientes haciendo cambios y regalos, además de otros usos que no pude notar. ${ }^{20-22}$

Las variedades de las especies de plantas nativas son comúnmente identificadas a través de sus características vegetales, como coloración, tamaño y sabor particular. La nominación normalmente indica dichas características o cualidades, como, por ejemplo, el avaxi ju (maíz amarillo) o la manduvi pytã guasu (granos grandes, de coloración roja) y la jety mandio (batata larga semejante a la mandioca). ${ }^{19}$ Son estas características particulares, según el profesor guaraní Tupã Jeguavy, las que pueden conferir legitimidad guaraní a la planta. Muchos cultivares son identificados por los guaraníes como plantas verdaderas, creadas por las divinidades para servir a los guaraníes en la alimentación, en la cura o en el uso instrumental. ${ }^{13,23}$ Dicha identificación se hace con el empleo del nombre de la planta acompañado por el sufijo ete siendo comúnmente utilizado cuando se dirigen a los blancos.

Este origen sagrado que aparece en los mitos tiene dos repercusiones en el régimen alimentario guaraní. Primeramente, asegura a los cultivares una posición central en el sistema alimentario guaraní y cierta preferencia por su consumo. Después, se asocian dichos vegetales a los modos deseables de una dieta para promover la ligereza corporal, una noción valorada en el pensamiento nativo y fundamental para la constitución de un marco de referencia para localizar las diferentes combinaciones alimentarias. ${ }^{12-14,24}$

Paradojalmente, plantas consideradas sagradas pueden dividir la misma roza con especies advenidas de los jurua** o con especies que tienen origen desconocido o ignorado, exceptuando el maíz verdadero para el cual se reserva un área privilegiada en Itamarã. A respecto del origen de las plantas, tengo la impresión de que se les autentican predicados divinos solamente cuando bajo estricta seguridad. Además de eso, el desconocimiento implica en el descaso absoluto de su procedencia. Como veremos, eso no inviabiliza su cultivo y consumo junto a otras especies.

Se sabe que el maíz tiene un papel de destaque en la sociedad guaraní..$^{3-5}$ La planta tiene implicaciones en el circuito sociológico de los intercambios entre parientes y de la movilidad entre aldeas, ${ }^{7}$ además de intermediar representaciones en el campo cosmológico, como, por ejemplo, en el mito narrado por Karai Poty del héroe Kuaray que usó mbyta (especie de pasta de maíz verde) para pegar los huesos y rehacer el cuerpo de su madre, que había sido devorada por jaguares. De ese

** Vocablo utilizado por los guaraníes para referirse a los no indígenas. 
modo, no sorprende que realicen a partir del maíz innúmeras recetas, incluso aquellas utilizadas en los ritos en su casa de rezo. ${ }^{12}$ Preparan una bebida fermentada denominada kaguyjy, consumida a diario durante sesiones de cante y baile ritual, además del mbojape, especie de pan servido especialmente con miel (ei) durante la ceremonia de nombramiento de los niños - el ñemongarai.

Con diferencias literales o literarias, en general las etnografías confieren una centralidad al maíz en la vida ritual guaraní y mucho se comenta sobre el tema. Cadogan ${ }^{25}$ describió en el período anterior a la plantación del maíz, la separación de mazorcas de la planta para ser llevadas hasta la opy donde serían ahumadas con el tabaco en un ritual denominado avaxi ñemongarai. También Ladeira, ${ }^{6,7}$ Assis $^{23}$ y Garlet ${ }^{8}$, describieron el ritual de nombramiento de los niños marcadamente unido al cultivo del maíz ete y que Cadogan ${ }^{25}$ igualmente localizó en el interior de una ceremonia más grande que celebra la cosecha y presenta los cultivares a las divinidades - el tembiu ñemongarai.

Tupã Jeguavy me explicó que las plantas consideradas sagradas tienen que ser "bautizadas" en la opy por intermedio del ahumado del petyngua (especie de pipa de madera) con algunos ejemplares cosechados en sus rozas. En Itamarã, una vez al año, realizan junto al ñemongarai el nombramiento de sus niños y la celebración de la cosecha del maíz avaxi ete. En esta ocasión las mujeres mayores preparan el mbojape y lo depositan en la opy para ser degustado tras la ceremonia. En otra época del año realizan el ritual exclusivo para "bautizar" sus alimentos sagrados como la miel, la yerbamate, el frijol, la batata. Eventualmente, si hay niños para ser nombrados, el chamán aprovecha la ceremonia para realizar dicho ritual.

Pese a que los parcos rozados de maíz distinguido como avaxi ete $i$ sean insuficientes para un deseado consumo más amplio, la hija del chamán- nombrador siempre guarda con ella ejemplares para servir en la sesión ritual. Sin embargo, observé que en Itamarã, en la falta de mazorcas de maíz ete'i para la fabricación del mbojape servido con miel a la mañana siguiente a la noche de cantes rituales del ñemongarai, otra variedad, pudiendo incluso ser adquirida junto a los blancos, se presta a la ceremonia. Igualmente, la sesión con uso de tabaco que precede la plantación y la ceremonia alimentaria en la que son presentados ejemplares de la cosecha, aunque no cuenten con la simpatía de todos, especialmente de algunos guaraníes mayores, las plantas ete’ $i$ pueden ser sustituidas por variedades adquiridas con los blancos. Al principio, tanto la ceremonia que precede la plantación como la que encierra el ciclo se relacionan con los alimentos que serán consumidos por los guaraníes. De ese modo, variedades no guaraníes de ciertas especies, en la falta de las originales, se prestan a ocupar su lugar en sesiones rituales, es decir, sirven exclusivamente para accionar un simbolismo relacionado al consumo. Queda excluido de ese proceso el producto engendrado en las relaciones con la alteridad jurua a través de la producción de maíz dirigida a los negocios en la ciudad. 
En Itamarã, además de trabajar en una roza colectiva donde generalmente plantan mandioca o maíz que generan los dividendos para su Asociación, las familias nucleares tienen rozados particulares. En él, mezclan la plantación de maíz, siendo muy habilidosos en su manejo, y, además de eso, producen otras especies usadas en su culinaria cotidiana y ritual.

Si los rozados en las hablas dirigidas a los blancos son identificados con los hombres, las mujeres, exceptuando las que están con la regla (impedidas de hacer este trabajo) y las mayores, en su mayoría se involucran casi que diariamente en las actividades de la roza. Tengo la sensación de que quizá lo más apropiado fuera asociar a los hombres la producción vegetal volcada a la negociación política de las cosechas con los blancos en la ciudad, por lo tanto, una actividad relacionada a la alteridad jurua. Las reuniones colectivas para las decisiones sobre la roza están limitadas a la participación de los hombres, aunque el proceso productivo no prescinda de la fuerza de trabajo femenina. Si la preparación de la tierra antes era una función masculina, hoy constituida como una etapa mecanizada en la aldea, la fase de sembradura cuenta en peso con la ayuda de las mujeres. La cosecha, a su vez, cuenta con la participación de ambos, teniendo, sin embargo, el empleo de la fuerza física masculina remunerada dentro de un juego complejo que puede involucrar la circulación de dones, reciprocidad y afirmación de las relaciones de parentesco.

En el trozo de tierra que cada núcleo dispone en Itamarã objetivamente emprendido en la producción con vistas a la venta, se mezclan otros cultivares alegremente cultivados por las mujeres como calabaza, cacahuete, banana, mandioca, sandía, frijol, caña de azúcar y batata. Consumen los vegetales crudos o asados, extraen zumos, elaboran ricos fermentados, fabrican harinas, preparados con harina de mandioca y revueltos, cocinan flanes, tartas y panes. Es decir, las plantas de las cuales se ocupan con más ahínco las mujeres son las que, como me afirmaron, "hacen crecer a la gente guaraní".

\section{Los jardines encantados y la unión con el divino}

Uso la palabra "jardín" contando con la imagen que evoca en la idealización de un espacio originario. Si en la antigüedad estos espacios construidos servían para buscar estados contemplativos o simplemente al convivio, remiten igualmente a la mitología judaico-cristiana del Paraíso o del Edén. Sin embargo, el origen del término, tomo la palabra jardín obviamente cercada de riesgos, para denominar esos espacios verdes que, por así decirlo, se prestan al cultivo de plantas alrededor de las casas. No siendo otra cosa que un jardín a la manera occidental, hago uso de la metonimia por la relación que mantiene asegurada la palabra con una forma originaria. Preferí jardín a huerto por parecerme un término potencialmente interesante para la metáfora aquí utilizada, es decir, la de un espacio por donde circulan procesos de recreación del cosmos y la unión originaria entre 
los guaraníes y las divinidades a través de la incesante réplica de plantas originales dejadas a los guaraníes. Por otra parte, huerto implica en la concepción de un conjunto de técnicas volcadas a la producción de especies domesticadas por el hombre cumpliendo un objetivo alimentario o medicinal y que, según interpreto, anclado en una racionalidad occidental que poco tiene que ver con la forma relacional que los guaraníes mantienen con sus plantas.

El contexto de la producción alimentaria se extiende desde los espacios localmente y colectivamente acordados como propicios para la producción, es decir, la roza delimitada para la plantación, hasta el entorno de las casas donde se puede observar los cultivares más o menos esparcidos. Allí se mezclan legumbres, tubérculos, raíces, cucurbitáceas, entre flores, hierbas y algunos condimentos traídos por los jurua como mejorana, hierba limón, salsa y perejil. Los mujeres se esmeran en el cuidado de dichos espacios en todas las atapas de trabajo. Allí las veía pasando algunas horas al día, incluso algunas veces cercadas de niños, limpiando las hierbas dañinas, haciendo huecos para depositar semillas y extrayendo vegetales para la elaboración de la comida.

Estos espacios contiguos a las casas sugieren poca preocupación con la estructura, sin embargo, bananos y cañas de azúcar están dispuestos en lugares estratégicos para no hacer sombra a las demás vegetaciones, además de otras combinaciones funcionales como entre gramíneas con leguminosas, raíces con cucurbitáceas y el espacio reservado para el maíz ete’ $i$. La prevalencia de una informalidad y despreocupación en la organización vegetal implícita en los canteros, desde mi punto de vista, sugiere la prevalencia de la centralidad de las plantas y cierta actitud contemplativa con su crecimiento.

Las plantaciones en locales cuidadosamente separados para el maíz ete’ $i$ y lo identificado como propio de los blancos se relata igualmente en otras etnografías.${ }^{6,7}$ Curiosamente, dicho cuidado se restringe al maíz. Considerando lo que mis datos permitieron evaluar, escuché descripciones de cultivares identificados como auténticos plantados conjuntamente con plantas oriundas de los blancos. Es decir, se combinaban variedades guaraníes y no guaraníes solamente de especies diferentes. Este es el caso en el que se encuentran los condimentos y las flores en los cultivares. Por otra parte, no encontré variedades guaraní y jurua de la misma especie dividiendo espacio en la roza, por ejemplo, frijol ete' $i$ mezclado con brotes de frijol adquiridos de los jurua.

Hay una cantidad significativa de árboles fructíferos plantados alrededor de las casas que fueron donados por asociaciones no-indígenas con el objetivo de mejorar la variedad de ítems alimentarios indígenas. Creciendo de modo disciplinado en el área contigua a la casa, para algunos servían menos para estimular el apetito que acomodar cómodamente en los días de intenso calor sus hamacas para tomar terere (bebida helada hecha con yerba-mate). Una u otra vez, se acordaban de contar entre risas que estas curiosas plantas producían tipos de frutos comestibles, según les dijeron los jurua. 
También este era el caso del proyecto de huertos pretendido por una ONG. Era posible identificar sus resquicios en algunas casas: un intento de arreglar simétricamente los canteros que, a su manera, los guaraníes acompañaban y cuidaban. Por otra parte, el descompás entre las expectativas de los jurua de un lado y las pretensiones de los guaraníes, de otro, aún incluía las especies a ser cultivadas. Era notoria la falta de pasión por las verduras y hojas disponibles en la plantación. El hecho era lamentado por los blancos más entusiastas en combatir lo que a sus ojos parecía ser una intrigante monotonía alimentaria y que en diversas ocasiones presencié intentando convencerles a los guaraníes a implementar sistemas de huertos. Los guaraníes se reían y me preguntaban si me gustaban las hojas verdes.

Por otra parte, no se puede dejar de notar que en los cultivares alrededor de las casas, de los cuales las mujeres se ocupan casi que exclusivamente, crecen vegetales destinados a la dieta cotidiana de la familia. Además de eso, el crecimiento de las plantas parece ser un tema que fácilmente moviliza los ánimos en Itamarã. Rozados con plantas frondosas eran celebrados por dueños altivos; en cambio, si no crecían, protestaban diciendo que posiblemente su crecimiento había sido interrumpido por celos*** de los vecinos. Cualquier actitud, por más pequeña que sea, actualiza una cara peligrosa del parentesco que amenaza el convivio. ${ }^{26}$

Sin embargo, eso no significa que los guaraníes resguardan sus rozas de las miradas ajenas o que sean recelosos de la atención comunitaria volcada al desarrollo de sus plantas. Sobre sandías, por ejemplo, el tema del deseo alimentario específico tiene enorme productividad, al contrario de relacionarse con la envidia. Frecuentemente el desaparecimiento de las frutas involucra la acción descuidada de los niños e inspiran una elaboración espirituosa del evento. Contando con el inevitable deseo ajeno de comer sandías suculentas que brotan prodigiosamente cercanas a las casas, frecuentemente estas situaciones eran vistas con cierto acuerdo velado y sin mayores rumores. La hija del chamán contaba en tono anecdótico sobre el robo de las frutas como "cosas que desaparecían del jardín”. Esta conducta se veía de manera muy diferente de la imbuida de codicia. "Y, al final, ¿̇ qué pasa con las sandías?”, le preguntaba. Me contestaba sonriendo: “Creo que los niños las vienen a comer".

Si la fuerza de una vegetación exuberante tiene gran significado entre los guaraníes es porque esperan tácitamente el crecimiento vegetativo bajo la perspectiva de quien sabidamente acompaña la reproducción de réplicas divinas reminiscentes de la morada de los dioses. El mbya Tupã Jeguavy y su esposa afirmaron que estas plantas guaraníes crecen hoy en los rozados guaraníes porque

\footnotetext{
*** Celos, akatey, y rabia, -poxy, tanto causan enfermedad a aquel que los produjo como a aquel a quien se dirigen los sentimientos; es el extremo de lo que se cultiva en el ámago del grupo y del modo adecuado de tratar parientes. Este tema tiene enorme productividad entre los guaraníes llevando en cuenta la tendencia de búsqueda de reafirmación del parentesco en la aldea. Señala una faz de instabilidad e inseguridad en el parentesco que en la mayoría de las veces, entre los guaraníes, despierta el deseo de cambio de aldea con el objetivo de no enfrentar situaciones que produzcan esta inseguridad. ${ }^{26}$
} 
crecieron originariamente en la casa de los dioses y siguen produciendo allá del mismo modo que producen aquí. Estos lugares son absolutamente encantados porque son la continuidad de aquellos otros, divinos, donde desean llegar. De ahí extraemos dos proposiciones. La primera sugiere que no hay una ruptura definitiva entre la esfera divina y humana, es decir, elaborado en términos guaraní, una distinción absoluta entre la Yvy Mara’é (Tierra sin mal) y la Yvy Pyau (Tierra Actual), sino una comunicación, que, entre otros modos, se manifiesta a través de la repetición de los vegetales allá y aquí. De eso declina la segunda proposición. Del mismo modo que la casa, dichos rozados expresan una relación genuina con la divinidad y la producción de la humanidad. ${ }^{24}$

Así se puede considerar la agricultura manifestando una forma laboriosa de fabricación del interior, de la vida doméstica, pero también su fuerza en la actualización de las relaciones con el dominio exterior, el socius, expresando, a su modo, la dependencia al mundo guaraní de sus dioses. La producción vegetal estaría al mismo tiempo actualizando la condición guaraní y su descendencia de la divinidad, además de reproducir simultáneamente, en la morada de los dioses y aquí en la tierra, las plantas sagradas. La espera para que las plantas broten y crezcan frondosas es como recibir dádivas, una vez que "Nanderu da y hace crecer", decía el Karai Poty.

La humanidad está entre la supranaturaleza y la naturaleza ${ }^{12}$ y las divinidades que conforman la base existencial humana también controlan los animales y hacen crecen los vegetales. El vegetal pertenece al dominio de la naturaleza, pero la naturaleza no se impone de forma absoluta a lo divino, reactualizando la unión entre humanos y dioses.

Si la divinidad está fuera del socius guaraní, buscan actualizar de otro modo su dependencia cotidiana a los dioses para la preservación de la persona y del propio socius. Se incluyen igualmente en las formas originarias de la sociabilidad guaraní los modos deseables de la vida humana que se estiman únicamente a partir de los presupuestos dejados por las divinidades. Observando y escuchando a los guaraníes mayores, creo que, en suma, lo que se busca retomar día tras día con estos bellos cultivares que crecen casi que espontáneamente bajo las miradas contemplativas guaraníes es la continuidad de la vida terrenal, el prolongamiento de la existencia de la persona a través de la recreación de lazos con la divinidad.

\section{Alegría y frugalidad y la dependencia divina}

Pienso que el aire contemplativo e incrédulo sobre los árboles fructíferos plantados alrededor de las casas, se inscribe en una perspectiva que denominaré frugal. En verdad, los buenos frutos son aquellos puestos por Ñanderu (divinidad) en el camino de los guaraníes; del mismo modo que los animales son puestos en el camino del cazador., ${ }^{6,23}$ Así, como la caza es una actividad comedida, los animales no deben ser abatidos excesivamente bajo pena de represalia del dueño espiritual de la especie, la reproducción vegetal requiere, de la misma manera, moderación, economía de energía. ${ }^{24}$ 
De ese modo, si el conjunto de actividades despendidas en la producción del maíz para los negocios con los blancos es visto como penoso, es porque se contrapone al crecimiento acompasado de los vegetales dejados por los dioses a los guaraníes y que son guardados alegremente. La reserva es que siguiendo la lógica de la sobriedad en las actividades cotidianas, los rozados de maíz que serán vendidos futuramente, aunque sean fatigantes, no escapan a la economía del comedimiento. Lo que se refleja en una adhesión bastante fluctuante de esta actividad regulada socialmente, principalmente en la medida que de ella se obtenga alguna ventaja. Aun así, contando con la coordinación de liderazgos, el mapa local de las actividades agrícolas volcadas a los negocios sigue de manera más o menos informal.

Mis observaciones sugieren que la sobriedad se aplica a todas las actividades cotidianas dado el comedimiento en involucrarse, en el uso de energía física y en la aplicación del deseo. Es perceptible no solo en las actividades consideradas penosas en la labra de la tierra, pero también en la recriminación del ahínco exagerado a la caza y en la conducta social o alimentaria intemperante.

Característicamente el cultivo de plantas alrededor de la casa implica en las mismas etapas de trabajo que ordinariamente se hacen necesarias en la agricultura occidental, exceptuando la corrección del suelo, el control de plantas invasoras y los tratos agrícolas, ${ }^{27}$ de ese modo, esta actividad sugiere pausas e informalidad comparativamente más grandes que las premisas de la horticultura convencional podrían soportar. En estos espacios verdes, las semillas se distribuyen aleatoriamente, hay mezclas de especies alimentarias entre flores e hierbas, falta de alineo de las plantas y una apariencia desordenada que desconsidera la simetría inspirada por la disposición de las plantas según un modelo decidido a priori y basado en formas geométricas. ${ }^{28}$

El comedimiento expresado por el número y la intensidad de las intervenciones humanas se une directamente a la provisión asegurada por los dioses del cosmos guaraní. Dicho de otra forma, si estas especies auténticas, réplicas de aquellas presentes entre los dioses, son designadas para el uso y provecho de los guaraníes, la divinidad actuará directamente en el levantamiento de las plantas. Es lo que me aseguraba el chamán siempre que le provocaba preguntando sobre el destino de sus rozas cuando viajaba y pasaba mucho tiempo lejos de casa. "Sembrar cabe a los guaraníes, pero no la prosperidad", me alertaba. El hacer levantar y el hacer crecer de las plantas es consecuencia de la actuación incisiva de Ñanderu. En mi entendimiento, para los guaraníes, el acto de cultivar se distancia de la actitud controladora y se acerca a modos concisos de actuación y una postura casi contemplativa propias a la "amitié respectueuse"28 que piden sus vegetales sagrados.

Estos modos de trato y cultivo de los vegetales por los guaraníes que respetuosamente esperan por el crecimiento espontáneo implican en aquello que Haudricourt ${ }^{28}$ denominó una acción indirecta negativa al hacer el análisis del cultivo del ñame en Nueva Caledonia "il n'y a jamais pour ainsi dire contact brutal dans l'espace ni simultanéité dans le temps avec l'être domestiqué". Esta acción indirecta que inspira un regreso a la naturaleza en el caso de los autóctonos de Nueva Caledonia 
sugiere para los guaraníes de aquí la recreación incesante de formas originarias, reactualizando su vínculo con las divinidades y la constante renovación de la vida en Yvy Pyau. No deja igualmente de estar relacionado al concepto de la Yuy Mara e’y, "la tierra que no tiene imperfección”, como me explicó cierta vez un cazador mayor. La intención de la recreación, en mi opinión, expresa antes la conciencia de la finitud y de la perennidad de la vida terrenal ${ }^{26}$ que únicamente una referencia al conjunto de prácticas económicas y ecológicas justificadas inequívocamente por la búsqueda de la Tierra Sin Mal. Como afirma Pissolato ${ }^{26}$ esta consciencia antes de representar una ruptura absoluta, entre, por así decir, la condición actual y otra profundamente anhelada entre las divinidades es la posibilidad, en los límites de la finitud de vida, sino de realizarla plenamente, cultivarla parsimoniosamente.

\section{Referências}

1. Meliá B. El guarani conquistado y reducido. Ensayos de etnohistoria. 4 ed. Asuncion: Centro de Estudios Antropológicos de la Universidad Católica; 1997.

2. Meliá B. A terra sem mal dos Guarani: economia e profecia. Revista de Antropologia 1990; 33:33-46.

3. Chase-Sardi M. El precio de la sangre: tuguy nee repy estudio de la cultura y el control social entre los Avá-Guaraní. Asunción: Centro de Estúdios Antropológicos; 1992.

4. Schaden E. Aspectos fundamentais da cultura guarani. São Paulo: EDUSP; 1974.

5. Cadogan L. Como interpretan los chiripás (Avá Guaraní) la danza ritual. Revista de Antropologia 1959; 7(1-2):65-99.

6. Ladeira MI. Espaço geográfico Guarani-Mbyá: significado, constituição e uso. São Paulo: Editora Unesp; 2008.

7. Ladeira MI. O caminhar sob a Luz. O território Mbyá Guarani e a beira do oceano. São Paulo: Editora Unesp; 2007.

8. Garlet I. Mobilidade mbyá: história e significação [Dissertação]. Porto Alegre: Programa de PósGraduação em História, Pontifícia Universidade Católica do Rio Grande do Sul; 1997.

9. Meliá B. El modo de ser Guarani en la primera documentatión jesuítica (1594-1639). Revista de Antropologia 1981; 24:5-6.

10. Clifford J. Sobre a autoridade etnográfica. In: Clifford J. A experiência etnográfica: antropologia e literatura no século XX. Rio de Janeiro: Editora UFRJ; 1998.

11. Geertz C. Local knowledge: further essays in interpretive anthropology. New York: Basic Books, 1983.

12. Tempass M. Quanto mais doce melhor. Um estudo antropológico das práticas alimentares da doce sociedade Mbyá-Guarani [Tese] Porto Alegre: Programa de Pós-Graduação em Antropologia Social, Universidade Federal do Rio Grande do Sul; 2010. 
13. Tempass M. Orerémbiú: a relação das práticas alimentares e seus significados com a identidade étnica e a cosmologia Mbyá-Guarani [Dissertação] Porto Alegre: Programa de Pós-Graduação em Antropologia Social, Universidade Federal do Rio Grande do Sul; 2005.

14. Clastres H. A terra sem mal, o profetismo Tupi Guarani. São Paulo: Brasiliense, 1978.

15. Hubert A. Ĺalimentation dans un village Yao de Thailande du Nord: De l'au-dela au cuisiné. Paris: CNRS; 1985.

16. McCallum C. Gender and sociality in Amazonia: how real people are made. Oxford: Berg; 2001.

17. Overing J, Passes A, organizadores. The anthropology of love and anger: the aestheics of conviviality in native Amazonia. London: Routledge; 2000.

18. Overing J. Elogio do cotidiano. A confiança e a arte da vida social em uma comunidade amazônica. MANA 1999; 5(1):81-107.

19. Filipim A. O sistema agrícola Garani Mbyá e seus cultivares de milho: um estudo de caso na aldeia Guarani da Ilha do Cardoso, município de Cananéia, SP [Dissertação] Piracicaba: Programa de Pós-Graduação em Ciências, Escola Superior de Agricultura Luiz de Queirós, Universidade de São Paulo; 2001.

20. Godbout JT. O espírito da dádiva. Rio de Janeiro: Fundação Getúlio Vargas; 1999.

21. Seeger A, Damatta R, Viveiros de Castro E. A construção da pessoa nas sociedades indígenas brasileiras. In: Oliveira Filho JP, organizador. Sociedades indígenas e indigenismo no Brasil. Rio de Janeiro: Marco Zero, UFRJ; 1987.

22. Mauss M. Ensaio sobre a dádiva: forma e razão da troca nas sociedades arcaicas. In: Mauss M. Sociologia e antropologia. v. II. São Paulo: EDUSP; 1974.

23. Assis V S. Dádiva, mercadoria e pessoa: as trocas na constituição do mundo social Mbyá [Tese] Porto Alegre: Programa de Pós-Graduação em Antropologia Social, Universidade Federal do Rio Grande do Sul; 2006.

24. Giordani RCF. Comportamento alimentar entre os Guarani. Cultura e alimentação [Tese] Curitiba: Co-tutela Programa de Pós Graduação em Sociologia, Universidade Federal do Paraná; 2012.

25. Cadogan L. Ayvu rapyta: textos míticos de los Mbya Guaraní del Guairá. Assunción: Fundación Leon Cadogan; 1997.

26. Pissolato E. A duração da pessoa. São Paulo: Unesp; 2007.

27. Souza J, Resende P. Manual de horticultura orgânica. Viçosa: Aprenda Fácil; 2006.

28. Haudricourt AG. Domestication des animaux, culture des plantes et traitement d'autrui. L'Homme $1962 ; 2(1): 40-50$. 